\title{
Desafios e perspectivas para a integração graduação/pós-graduação em Ciência da Informação: o caso do ICI/UFBA ${ }^{1}$
}

\section{Maria Yêda Falcão Soares de Filgueiras Gomes}

\section{Professora Permanente do PPGCI, Instituto de Ciência da Informação, Universidade Federal da Bahia}

Este texto apresenta alguns resultados da pesquisa "Ciência da informação no Brasil: desafios atuais para a consolidação do campo". Ele discute a questão da integração entre a formação propiciada pela pósgraduação e a formação profissional oferecida na graduação, a partir de um estudo de caso no Programa de Pós-Graduação em Ciência da Informação da UFBA. Para buscar subsídios sobre essa integração, entrevistou-se, pessoalmente, 12 professores de ambos os níveis de ensino, dos quais nove atuam na pós-graduação e na graduação e três somente na graduação. Eles discutiram as possibilidades e limites dessa integração; a adequação do perfil do docente pós-graduado às necessidades da graduação; e o papel que a pesquisa pode desempenhar nessa integração. Dentre as ações indicadas como necessárias para melhorar essa integração, sugere-se maior articulação entre os currículos desses dois níveis de ensino; maior interlocução entre os colegiados de graduação e pós-graduação; ampliação da oferta de bolsas de IC e democratização do acesso a elas; investimento na infraestrutura física e tecnológica do ICI a ser compartilhada pelos dois níveis de formação, bem como a ampliação do número de programas de pósgraduação da área, distribuindo-os de forma mais equitativa pelas regiões do país.

Palavras-chave: Integração graduação/pós-graduação e pesquisa em Ciência da Informação; Desafios atuais; Brasil.

1 Projeto em desenvolvimento, com Bolsa de Produtividade em Pesquisa do CNPq-PQ2, processo $n^{\circ}$. 308763/2009-2. 


\section{Challenges and perspectives in the integration of undergraduate and graduate studies in information science: the ICI/UFBA case}

This text presents some results of the research 'Information science in Brazil: facing the present challenges to consolidate the field'. It discusses aspects related to the integration between professional readiness at undergraduate level and graduate studies, based on a case study in the graduate program in information science at UFBA. To get information about this integration, we personally interviewed twelve professors, nine of whom teach at both levels; three only at graduate level. They discussed the potentialities and the limitations of this integration; the compatibility of the graduate student's profile with the needs of graduate studies; and the role research can play in this integration. The actions suggested to improve this integration include better articulation between the curricula for these two levels of study; more effective interlocution between the undergraduate and graduate boards; increase in the number of scholarships in the area of information science and democratization of selection policies; investments in the physical and technological structures of the Institute of Information Science, which is to be shared by both levels; increase in the number of graduate programs in this area, as well as a more equitable way of distributing them within the different regions in Brazil.

Key words: Integration undergraduate/graduate and research in information science; present challenges; Brazil.

Recebido em 28.07.2011 Aceito em 02.07.2012

\section{Introdução}

É inegável o avanço que teve o ensino em nível de pós-graduação no Brasil, nesta primeira década do século XXI, com a expansão do número de programas e o aperfeiçoamento dos critérios de avaliação utilizados pela Capes. Só no último triênio de avaliação, correspondente ao período 2007-2009, foram avaliados 2.718 programas em todas as áreas - $20 \%$ a mais do que na avaliação anterior, tendo um terço deles 
(33,9\%) obtido nota 4, em uma escala que vai de 1 (pior) a 7 (melhor). A Grande Área de Ciências Sociais Aplicadas I, integrada por três áreas do conhecimento - Comunicação, Ciência da Informação e Museologia oferece, atualmente, 52 Programas, enquanto em 2000, ela oferecia apenas 19; a Ciência da Informação também cresceu, ainda que a um ritmo um pouco inferior ao da Grande Área como um todo, uma vez que, em 2000, havia somente 5 Programas em Ciência da Informação e, dez anos depois, eles já eram 12, compostos por 6 Programas com Mestrado e Doutorado, 5 Mestrados e 1 Mestrado Profissional, este último, o primeiro da área ${ }^{2}$. Estes Programas distribuem-se geograficamente da seguinte maneira: dois na região Sul $(16,6 \%)$, seis na região Sudeste $(50 \%)$, três na região Nordeste $(25 \%)$ e apenas um Programa $(8,3 \%)$ na região Centro-Oeste. Houve, assim, um crescimento dos Programas da Grande Área de Ciências Sociais Aplicadas I da ordem de $54 \%$ em relação àqueles avaliados no último triênio, sendo que na Comunicação esse crescimento foi de $58 \%$ e na Ciência da Informação, de $50 \%$. A Museologia continua com um único Programa de Mestrado (BRASIL, 2010).

Com exceção desta última área, o atual panorama sinaliza uma evolução bastante positiva. Estes últimos 10 anos apontam, portanto, para a consolidação da Ciência da Informação, com uma significativa ampliação da formação de mestres e doutores e com a decorrente institucionalização da pesquisa, na medida em que parte importante desses novos titulados passa a dedicar-se a atividades de ensino superior e a responder aos requisitos exigidos para o acesso aos financiamentos das agências de fomento à pesquisa.

Considerando que a interlocução entre graduação e pós-graduação parece ser tradicionalmente restrita em nossa área, a questão central explorada, neste trabalho, passou a ser: a partir da evolução positiva no processo de consolidação da área, como ampliar essa interlocução, de modo que esses dois níveis de formação se reforcem e se enriqueçam mutuamente?

De um modo geral, a dificuldade de integração entre graduação e pós-graduação é uma questão que se coloca nas diferentes áreas do conhecimento, ainda que haja, em algumas delas, uma maior aproximação entre esses dois níveis de ensino, através da implementação de diretrizes e o desenvolvimento de atividades que favoreçam e estimulem essa integração. Em um levantamento sobre o tema ${ }^{3}$, encontrou-se menção a algumas tentativas com essa preocupação, dentre as quais poderiam ser incluídos os cursos do Programa de Pós-GraduaçãoPPG em Filologia e Língua Portuguesa do Curso de Letras da FFLCH da USP, no qual as disciplinas ministradas na graduação estão relacionadas a atividades de pesquisa desenvolvidas por esse Programa; a do

\footnotetext{
${ }^{2}$ Em sua avaliação anual realizada em 2011, a CAPES autorizou o funcionamento de mais 2 Doutorados: um no PPGCI da UFSCar e o outro no PPGCI da UFPb, além de mais um Mestrado Profissional no PPGARQPrograma de Pós-Graduação em Gestão de Documentos e Arquivos, da UNIRIO, os quais deverão ser implantados neste ano de 2012.

${ }^{3}$ Informações colhidas através da literatura especializada e, também, de informações disponibilizadas em sítios institucionais dos programas mencionados.
} 
Departamento de Serviço Social da UnB, que elaborou, em 2006, uma política e diretrizes para promover a integração entre o PPG em Política Social e o curso de graduação; a do UNICEUB-Centro Universitário de Brasília, que propôs, em 2007, um Projeto de Integração Pós-GraduaçãoGraduação; a do PPG em Ecologia da Universidade Federal de Juiz de Fora, que propôs a articulação entre ensino e pesquisa, através da interação de conteúdos da graduação e pós-graduação por meio de seminários integrados, participação em projetos e em outras atividades e eventos comuns; a do Mestrado em Políticas Públicas e Sociedade, da Universidade Estadual do Ceará; ou, ainda, a do PPG em Psiquiatria da Universidade Federal de São Paulo, entre outros ${ }^{4}$.

No caso da UFBA, essa integração, como fator de qualidade na educação superior, vem sendo periodicamente colocada em discussão, ainda que com avanços, retrocessos eventuais e descontinuidades. Observa-se, de um modo geral, que existe um distanciamento entre esses dois níveis de formação, sendo, via de regra, ainda limitadas as iniciativas que levam a uma maior articulação entre graduação/pesquisa/pósgraduação. A maneira mais "tradicional" de encarar a questão considera que essa plena integração tem seus limites, na medida em que, tanto a graduação quanto a pós-graduação, teriam objetivos próprios, claros e bem definidos. Ou seja, o foco principal da graduação estaria na formação de profissionais competentes para atender às necessidades do mercado de trabalho em áreas específicas e a pós-graduação stricto sensu teria na formação de docentes e pesquisadores para o ensino superior, centros e instituições de pesquisa, o seu objetivo central. Embora se afirme que o ensino, a pesquisa e a extensão são os três pilares em que a universidade se apoia, na prática, a importância atribuída a cada um deles é diferenciada, uma vez que a articulação entre esses três pilares, em geral, é restrita (ou mesmo inexistente), incluindo, no máximo, aquelas tentativas de articulação entre os níveis de ensino de graduação e pósgraduação.

A literatura sobre este tema na área de Ciência da Informação é relativamente escassa, sendo, aí, poucos os textos com essa preocupação: ou se trata de trabalhos sobre a formação na graduação ou na pós-graduação, sendo mais raros aqueles focados nas relações entre ambos os níveis de formação. Diante desta lacuna, perguntou-se: como vem ocorrendo a articulação entre o que se pesquisa na área, a maneira como se estrutura a pós-graduação e a formação profissional que se oferece na graduação? Pôde-se constatar que alguns docentes/pesquisadores vêm se preocupando com este assunto, bem como a Associação Brasileira de Educação em Ciência da Informação

\footnotetext{
${ }^{4}$ Dentre os eventos científicos que abordaram o tema, destacaram-se o VI Simpósio de Pesquisa da Associação Nacional de Pesquisa e Pós-Graduação em Psicologia-ANPEPP, realizado em Teresópolis, em 1996; O I Seminário de Integração Graduação/Pós-Graduação, realizado pela Faculdade Paranaense, em $11 \mathrm{e}$ 12/05/2007; o XXXV Congresso Brasileiro de Educação em Engenharia-COBENGE, 2007 2F04-1, Integração Graduação e Pós-Graduação, pela UFSCar; o $1^{\circ}$. Encontro de Integração entre a Pós-Graduação e a Graduação da UninCor, em 27/10/2011, realizado pelo mestrado em Clínica Odontológica da Universidade Vale do Rio Verde, campus Três Corações, com a finalidade de promover a união e a integração do corpo docente e discente (inclusive ex-alunos) de graduação em Odontologia.
} 
(ABECIN). Em pesquisa sobre a evolução quantitativa dos cursos de graduação na área, Arboit, Bufrem e Kobashi (2011) constataram que a tendência de crescimento da quantidade dos cursos de graduação reflete a importância dada à informação no contexto atual, e destacam, logo na sua introdução:

Embora a pesquisa substantiva e sistemática em CI no país tenha tido início nos programas de pós-graduação da área, ligados às escolas de Biblioteconomia, é inegável que o desenvolvimento da CI ocorre também no âmbito da graduação. Este representa o enfoque mais prático de preparação de profissionais para atuação em variados dispositivos de informação, em diferentes contextos, como também de preparação para a pesquisa, por meio de Iniciação científica e elaboração de Trabalhos de conclusão de curso (TCCS) (ARBOIT; BUFREM; KOBASCHI, 2011, p. 145).

Claro que essa relativa ausência de estudos sobre o tema se explica pelo fato de, na maioria das instituições de ensino superior, só existir formação no nível de graduação nas áreas de Biblioteconomia e afins. Porém, a rápida expansão das atividades de pós-graduação e pesquisa em Ciência da Informação, mencionada acima, torna, cada vez mais, pertinente o questionamento.

Para aproximar-se do tema, a partir de um caso concreto, decidiu-se discutir e refletir sobre como o problema se apresenta no Programa de Pós-Graduação em Ciência da Informação - PPGCI do Instituto de Ciência da Informação da Universidade Federal da Bahia-ICI/UFBA. Esse Programa foi criado em 1998, para atender a demanda da sociedade local, regional e nacional por formação de professores-pesquisadores na área, nos níveis de Mestrado e Doutorado ${ }^{5}$. Ele tem como área de concentração Informação e Conhecimento na Sociedade Contemporânea, nela se inserindo duas linhas de pesquisa: 1)Políticas, tecnologias e usos da informação; e 2) Produção, circulação e mediação da informação. Entrevistou-se, pessoalmente, professores da pós-graduação e da graduação, em busca de mais subsídios sobre a realidade atual e perspectivas para essa integração. Optou-se deliberadamente pela realização de entrevistas abertas e não por questionários fechados, que pudessem ser posteriormente quantificados, justamente para permitir que fluíssem livremente as diferentes visões dos docentes de ambos os níveis sobre o assunto.

Com essa perspectiva, esta comunicação está estruturada em quatro partes, além da Introdução. Na primeira, apresentamos a metodologia utilizada na pesquisa; reuniu-se, na segunda e terceira partes, os principais temas abordados nas entrevistas, procurando destacar e analisar as posições convergentes e/ou divergentes apresentadas pelos entrevistados e, na quarta parte, desenvolveu-se as considerações finais.

\footnotetext{
${ }^{5}$ Embora este último só tenha sido implantado no $2^{\circ}$. semestre de 2011 , após a consolidação da experiência do Mestrado.
} 


\section{Delineamento da pesquisa}

As entrevistas com os professores do ICI/UFBA tiveram como objetivos específicos discutir os diferentes aspectos que interferem no processo de integração graduação/pós-graduação, os mecanismos que poderiam facilitar a articulação entre esses dois níveis de ensino e os desafios a vencer. Para tanto, no primeiro semestre de 2009, realizou-se entrevistas pessoais com nove professores, que atuam, simultaneamente, na pós-graduação e na graduação, e com mais três que se dedicam apenas à graduação, perfazendo um total de doze docentes. ${ }^{6}$ Elaborou-se um roteiro com questões em aberto, que versaram sobre as relações atuais entre a graduação e a pós-graduação na instituição; sobre as ações necessárias para melhorar os mecanismos de articulação entre esses dois níveis; sobre as possibilidades de potencializar o impacto positivo da melhor qualificação dos professores (mestres e/ou doutores) na graduação, assim como sobre o diálogo e a retroalimentação entre esta e a pós-graduação, procurando, também, saber como a produção científica dos docentes que atuam nesses dois níveis articula-se no plano do ensino. Finalmente, tentou-se obter informações sobre a adequação da formação dos egressos da pós-graduação do ICI diante das necessidades do ensino de graduação, além de solicitar comentários dos entrevistados sobre experiências eventualmente bem sucedidas entre esses dois níveis.

As entrevistas foram gravadas e tiveram a duração de mais ou menos uma hora cada. Os argumentos dados nas respostas dos professores foram agrupados por temas tratados e posteriormente analisados. Os resultados são apresentados a seguir, de acordo com cada um dos grandes eixos que fizeram parte da entrevista.

\section{Integração graduação/pós-graduação em CI no ICI/UFBA}

Em artigo sobre o papel da pesquisa em cursos de graduação em Ciência da Informação, Kobashi (2002) chamou a atenção para a importância da integração desse nível de ensino com a pós-graduação, como fator decisivo para a consolidação da área, afirmando que esta era uma tarefa urgente que se colocava para as instituições, onde já existiam cursos de pós-graduação. Em outro trabalho apresentado em 2004, sobre esse mesmo tema, essa autora sugeria duas ações que, se conjugadas, poderiam indicar caminhos para a resolução de problemas nesse campo: 1) multiplicar os programas de pós-graduação da área, distribuindo-os de forma mais equitativa pelas regiões do país; e 2) estabelecer políticas que priorizassem, na seleção, aqueles candidatos que aliam ao mérito de novas propostas à perspectiva de inserção em atividades acadêmicas. Segundo ela, reforçar-se-ia, com essa política, a formação de quadros para o ensino superior em Ciência da Informação (KOBASHI, 2004).

\footnotetext{
${ }^{6}$ Dois professores da pós-graduação/graduação encontravam-se, naquele momento, realizando pós-doutorado.
} 
Documentos produzidos pela Associação Brasileira de Ensino de Ciência da Informação (ABECIN), no âmbito de variados fóruns, realizados nesses últimos anos, voltados para a discussão e proposição de diretrizes para o ensino, também destacavam a importância da formação científica na graduação, a necessidade de uma integração mais orgânica entre esta e a pós-graduação e a busca do aperfeiçoamento de seus vínculos?

É, em torno dessa problemática, que se situa o primeiro tema das entrevistas. A maioria dos respondentes destacou que, na prática, não existe essa integração e que isso aconteceria por várias razões. Dentre elas, as de natureza conceitual, as de natureza institucional e as que dizem respeito à infraestrutura. Conforme argumenta um entrevistado, "quem sai da graduação em Biblioteconomia ou Arquivologia, submete-se a um programa de Ciência da Informação, que não dá continuidade ao que ele fez na graduação; há uma ruptura". Do ponto de vista institucional, considera que há algumas medidas como as bolsas de iniciação científica e a possibilidade de estudantes voluntários participarem de grupos de pesquisa, embora com as limitações advindas da falta de ligação entre o que aprendem e vivenciam no cotidiano da graduação e o que devem desenvolver na pesquisa. Outra entrevistada também lembra que a Ciência da Informação, no Brasil, é estudada basicamente na pós-graduação e que a graduação encontra-se afastada da evolução dessa área, o que torna mais complicada a interação entre esses diferentes níveis de formação. Uma terceira respondente ressalta que o distanciamento entre graduação e pós-graduação "não é só um problema dessa área; esse afastamento é uma constante e muitos programas e organismos de fomento já vêm, há alguns anos, procurando aproximar esses dois níveis de ensino". Para ela, a pesquisa seria justamente um dos mecanismos mais eficazes para essa integração. Com argumento semelhante, outro entrevistado observa que é nos grupos de pesquisa que se dá início a essa articulação entre graduandos e pósgraduandos, através das reuniões internas e outras atividades dos grupos, incluindo, aí, publicações conjuntas.

Outra professora também destaca que deveria haver disciplinas na graduação que tivessem aprofundamento na pós-graduação; ou seja, que se buscasse algum tipo de diálogo, ainda que pontual, entre disciplinas da grade curricular da graduação e da pós-graduação. Em termos de estrutura curricular, ela não vê integração entre esses dois níveis de ensino. No entanto, para outra entrevistada, haveria sim possibilidade de alguma articulação curricular, argumentando que "a pós-graduação vem com duas disciplinas básicas que podem dar continuidade à graduação: a Epistemologia e a Metodologia." Segundo ela:

Esta vem esclarecer e também dar continuidade à disciplina Metodologia que há na graduação e que os alunos já vêm, pressupõe-se, para a área de metodologia ampliar a discussão de procedimentos, de se aproximar do objeto de estudo. E, na

\footnotetext{
${ }^{7}$ Disponível em: <www.abecin.org.br/portal/index.phpdocumentos-abecin >. Acesso em: 24 nov. 2011
} 
Epistemologia, se continua a discutir o conceito de Ciência da Informação e toda a integração com outras áreas do conhecimento e as raízes, etc. Juntando a epistemologia com a metodologia, é o casamento perfeito para complementá-la.

Sobre essa questão conceitual, Amaral (2004), ao fazer algumas considerações sobre os programas de pós-graduação em Ciência da Informação no Brasil, já destacava:

A graduação em Biblioteconomia, de um modo geral, não se vê como parte integrante da Ciência da Informação e preconiza uma visão mais tecnicista do que tecnológica, o que pode explicar o distanciamento entre a Biblioteconomia e a Ciência da Informação, e estimular as discussões filosóficas e epistemológicas sobre a Ciência da Informação. Tal situação resulta na percepção das grandes contradições da área. Apesar da necessária aproximação entre a ANCIB e a ABECIN, que deve ser buscada, a integração entre a graduação e a Pós-Graduação em Ciência da Informação ainda não se reflete em ações e realizações conjuntas entre a ANCIB e a ABECIN (AMARAL, 2004, p. 60).

Na visão de outra professora, as possibilidades de articulação entre esses dois níveis é muito limitada ou praticamente só existe "para alguns pesquisadores específicos que encontraram em alguns alunos de graduação uma perspectiva de continuidade", e afora isso, afirma que "não existe como uma vontade de envolver as turmas de graduação para um entendimento desse processo". Destaca que isso só ocorreria através das bolsas de iniciação científica ou mesmo do trabalho de voluntários em pesquisas docentes, o que conferiria a esses alunos uma formação diferenciada, embora isso, na prática, atinja um número restrito de alunos. Neste sentido, ela ressalta que, ainda, é muito restrita a contribuição da pós para melhorar e fortalecer o ensino de graduação no ICI, limitando-se à obtenção de verbas um pouco maiores para melhorar a infraestrutura tecnológica, compra de material permanente, como livros e equipamentos, e de consumo, além de permitir trazer periodicamente convidados externos.

Vários entrevistados constataram, entretanto, que, nos últimos anos, tem havido uma busca mais intensa de integração, justamente com o crescimento e ampliação dos programas de iniciação científica.

Apesar de diferenças nas suas falas e na maneira de refletir sobre o tema, ações foram indicadas como necessárias para melhorar os mecanismos já existentes e mesmo apontar outros, de modo a intensificar e consolidar essa integração. Considera-se importante, portanto, a reestruturação curricular dos cursos de graduação e a possibilidade de se mapear aquelas disciplinas que favoreceriam a realização de pequenas pesquisas, que cumpririam um papel de "iniciação" à atividade de investigação. Outras sugestões foram a inclusão, no currículo de 
graduação, de disciplinas que pudessem se articular ao currículo da pósgraduação, ou, ainda, o estímulo para que os alunos da graduação cursassem disciplinas optativas da pós, com direito à obtenção de crédito. Sugeriu-se, ainda, que os programas de pós-graduação, da mesma forma que reservam um número de vagas para alunos especiais já graduados, abrissem, também, vagas, para que, através de um processo seletivo, os alunos de graduação pudessem cursá-las junto com os de pós-graduação.

Um dos entrevistados lembra a importância de se ter regras claras para estimular e/ou ampliar essa integração, pois, muitas vezes, ela se situa em um plano muito pessoal e informal, dependendo de quem é o professor e de como ele se relaciona com os alunos. Outra sugestão diz respeito à necessidade de se incrementar a circulação da informação entre esses dois níveis, de modo a ampliar para o conjunto de alunos do ICI o conhecimento das atividades desenvolvidas no Programa de pósgraduação, além de fomentar a integração entre a graduação e pósgraduação nos espaços de informação, como bibliotecas e laboratórios. Com essa perspectiva, haveria maior conhecimento e maior vivência das questões enfrentadas nas linhas, grupos e projetos de pesquisa. Finalmente, o aumento do número de pesquisadores na pós-graduação e o investimento na infraestrutura física e tecnológica do ICI, a ser compartilhada pelos dois níveis de formação, seriam outras tantas formas de melhorar essa integração.

\section{Perfil do docente/pesquisador e necessidades da graduação}

Ao abordar a questão do perfil do docente que leciona na graduação, Rodrigues (2004, p.172) refere-se, entre outros aspectos, ao princípio pedagógico do ensino articulado à pesquisa nos cursos de graduação e afirma que "esse princípio pedagógico requer articulação entre a teoria e a prática e somente encontrará seu pleno sentido na medida em que a graduação e a pós-graduação se articularem, efetivamente". E, mais adiante, conclui, ao dizer que:

Espera-se que a pós-graduação proporcione ao professor uma formação científica que leve ao domínio dos processos de produção e inovação do saber e, consequentemente, domínio dos métodos de investigação. Com esse preparo, o professor será capaz de conduzir os alunos da graduação a formas básicas de investigação, familiarizando-os com os métodos para a construção do conhecimento em suas respectivas áreas de formação (RODRIGUES, 2004, p. 172).

Também não observou-se unanimidade nas respostas dos entrevistados, no que diz respeito ao tema da adequação ou não do perfil desse docente pós-graduado. Um deles considera que este é um problema que concerne a todo o país e que, na maioria das vezes, nas áreas de Biblioteconomia e Ciência da Informação, é muito difícil essa adequação, justamente pelo próprio fato de que há uma ruptura entre os programas e 
conteúdos da graduação e da pós-graduação. Outra entrevistada ressalta que, quando se abre um concurso público para docente, tem que se decidir qual é o perfil de docente que se busca, e que, nesse processo de decisão, poder-se-ia definir qual é a interação esperada desse professor no curso de graduação, devendo ser avaliado, também, caso o candidato seja egresso de outra área, se ele seria capaz de introduzir os conhecimentos e práticas necessários para ampliar essa articulação. Observa, ainda, que, com relação às disciplinas da graduação, sua distribuição entre os docentes acaba sendo, muitas vezes, nas palavras da depoente, meio "caótica", devido à necessidade de se assegurar o oferecimento daquelas que estão sem professor e que isso, do ponto de vista da qualidade do ensino, pode não ser o mais desejável. Segundo ela, a interlocução entre colegas, através da discussão dos conteúdos das disciplinas ofertadas a cada semestre, reunidos por núcleos, favoreceria as possibilidades de articulação; a mesma coisa deveria ocorrer com a pósgraduação.

"Não há diálogo entre os dois níveis de ensino [...] e não existe integração dos colegiados com os departamentos", ressalta outra entrevistada, para lembrar como é difícil fazer essa articulação. Para ela, não existiria adequação alguma entre a formação dos docentes pósgraduados e as necessidades da graduação e que isso vai, provavelmente, se refletir no currículo novo que entrou em vigor em 2010.1, porque ele nem refletiria o que vem de novo com as pessoas formadas na própria instituição ou em outras, nem refletiria as necessidades da graduação. Destaca, ainda, que existe carência de professores em subáreas, como, por exemplo, a de representação e recuperação da informação, e que se deveria discutir, a cada semestre, a atualização de suas disciplinas e respectivos programas.

$\mathrm{Na}$ percepção de outro respondente, deve-se considerar vários aspectos quanto à adequação ou não do perfil do docente/pesquisador: para ele, esse perfil pode existir "teoricamente", mas, na prática, possui diferentes níveis de adequação, e isto por várias razões, como, por exemplo, cada um vai discutir os conteúdos tratados segundo sua bagagem e dentro de sua área de origem (caso provenham de outra área). Além disto, afirma que os alunos percebem esse diferencial da origem "disciplinar" dos professores em seu comportamento, nas suas atitudes em sala de aula, na maneira de discutir e nos focos dados a determinados conteúdos, que variam dependendo da formação de cada um. Para outro entrevistado, nas áreas interdisciplinares ou com conteúdo social mais acentuado, essa adequação seria mais fácil de ser alcançada; porém, naquelas áreas que exigem conhecimentos técnicos específicos, pode-se notar maior inadequação.

O posicionamento de alguns entrevistados sobre esse tema diverge um pouco dos acima mencionados: um deles observa que há uma adequação, mas, às vezes, o currículo de graduação está muito aquém daquilo que se discute (e para o qual o professor se capacitou) na pósgraduação. Nestes casos, caberia ao docente, que está em sala de aula, fazer essa mediação e introduzir ajustes que incluam itens necessários e 
mais atuais, mas que, ainda, não constem no currículo atual de graduação.

Já outra docente destaca que o fato de vários professores terem feito o mestrado e/ou o doutorado em outras áreas do conhecimento enriquece muito suas experiências acadêmicas, pois eles passam a incorporar uma visão mais ampla e, logicamente, a repassá-la para seus alunos, contribuindo para a criação de uma interdisciplinaridade da qual se fala muito e pouco se pratica, esforço este que não passa despercebido dos alunos. Nessa mesma linha de reflexão, uma respondente afirma que esse enriquecimento tem vários aspectos e ressalta que a prática corrente na pós-graduação, a da leitura, debate e discussão de textos e projetos, enfatizando as diferenças nas abordagens teóricas e metodológicas, começa a se reproduzir nas salas de aula da graduação, o que já é, em si, muito positivo. Considera, ainda, que, qualificando-se, o professor vai ter maiores possibilidades de desenvolvimento de projetos que envolvam alunos de graduação e que propiciem a eles uma maior convivência com os alunos de pós-graduação. Quanto à adequação/inadequação do perfil do docente pós-graduado às necessidades da graduação, ela diz que:

[...] há necessidade de avançar, pois "ele tem que ser doutor e pesquisador das temáticas que aquelas disciplinas do concurso que ele está se submetendo exigem que ele seja, para que ele possa entender inclusive que profissional ele está ajudando a formar."

Ao afirmar que esses profissionais são bem capacitados e que cumprem o seu papel, outra professora acaba levantando questões de outra natureza, como a falta de infraestrutura do ICI em termos de laboratórios, equipamentos, biblioteca, o que faz com que pessoas capacitadas e com boa formação não disponham desse instrumental básico que atenda a suas necessidades de ensino. Isto "é uma questãochave", conclui ela, embora, a essa visão, poder-se-ia contrapor àquela que percebe e registra tentativas de melhoria ora em curso no ICI.

Mesmo considerando que existe adequação do perfil docente às necessidades da graduação (e que, mesmo quando não é este o caso, nota-se uma busca de "ajustamento" por parte dos docentes), outra respondente percebe, também, que o ensino nos dois níveis ainda se retroalimenta pouco, face a sua potencialidade, e que é preciso haver mais articulação entre eles, estimular o compartilhamento entre as coordenações da pós-graduação e da graduação, pois isso leva automaticamente a pensar em conjunto e na mesma direção. Sem isto, a prática do ensino fica fragmentada, cada qual atuando isoladamente e pensando apenas em seu espaço.

Dentro ainda da temática do perfil do docente/pesquisador, perguntou-se aos entrevistados se a participação de professores doutores 
no ensino de graduação contribuiria para uma maior maturidade do aluno no processo de aprendizagem.

Um professor estima que dos 20 alunos que integraram em algum momento seu grupo de pesquisa, em torno de $20 \%$ deles terminaram se interessando, de fato, pela atividade de pesquisa e acabaram se encaminhando para o mestrado, com o projeto de se dedicarem à carreira docente. Na própria graduação, estima outra entrevistada, o professor poderia estimular, em sala de aula, um melhor entendimento do aluno sobre a pós-graduação, motivando sua vontade de cursá-la posteriormente. Uma maior participação de alunos de graduação em eventos científicos é, também, notada: outra professora destaca que eles se sentem estimulados a escrever, falar, escutar, estar presentes tanto nos eventos promovidos localmente como naqueles realizados em outros estados. Considera que o professor, mesmo que não seja de metodologia, mas de outras disciplinas, deve incentivar seus alunos a escreverem artigos para revistas e a ajudá-los nesse sentido, o que, segundo ela, já está acontecendo e é um reflexo de uma melhor qualificação docente. Esta mesma professora considera, ainda, que quando ela própria ensina a disciplina Metodologia, existe, sim, articulação entre esta e a pesquisa que ela desenvolve dentro do seu grupo de trabalho, pois dá para fazer essa articulação e mostrar aos alunos as várias "visões", os vários cenários em que se pode trabalhar com a Ciência da Informação.

\section{Considerações finais}

A que problemas, desafios e perspectivas essas falas, às vezes tão contraditórias, remetem? Andrade (1999), ao referir-se à flexibilização da pós-graduação em editorial da revista Química Nova, destacou que a integração graduação/pós-graduação ocorre basicamente na melhoria da qualificação dos docentes e na atuação dos professores dos cursos de pósgraduação em aulas na graduação, em projetos desenvolvidos no âmbito de programas específicos, com a finalidade de promoverem esta articulação e na orientação de estudantes de iniciação científica ${ }^{8}$. Considerou, também, que, na maioria das vezes, essas ações são individualizadas e desordenadas e que, ainda,

[...] esta integração deverá evoluir de forma a resultar numa ampla articulação didático-científica, visando a melhoria do ensino de graduação, e que permita, entre outros, o acesso amplo de seus estudantes (bolsistas ou não) a cursos e atividades da pós-graduação, bem como aos estudantes da pós-graduação atuarem no ensino e graduação, para complementação da sua formação pedagógica (ANDRADE, 1999).

Com reflexões semelhantes, Cury (2004, p. 790), em artigo que teve como objetivo indicar, na situação presente das instituições

\footnotetext{
${ }^{8}$ Citou como exemplo o Programa Integrado entre Pós-Graduação e Graduação (PROIN), que vigorou na UFBA durante certo período.
} 
universitárias, a relação entre a graduação e a pós-graduação como forma institucional de preencher a indissolubilidade entre ensino, pesquisa e extensão, considera que para que essa relação possa ir além da qualificação de docentes, é necessário "traçar uma radiografia mais detalhada da situação atual, que, com a participação de órgãos colegiados e de gestores universitários, ofereça alternativas tendo em vista uma relação mais integrada e dotada de uma circularidade virtuosa". E, mais adiante, explica que essa relação de circularidade virtuosa entre ambos os níveis seria

[...] positiva tanto para a graduação como para a pósgraduação, sendo que a melhoria na primeira conduz a um mais alto desempenho dos formados em sua profissionalização e permite estudantes mais bem preparados para uma atuação dinâmica da pós-graduação (CURY, 2004, p.791).

Visando abrir perspectivas de atualização da estrutura acadêmica vigente na UFBA, em 2007, foi aprovada a oferta dos bacharelados interdisciplinares como primeiro ciclo para oitenta e uma opções de graduação, no âmbito da proposta Universidade Nova (UN), cujo objetivo principal é justamente a reestruturação do modelo acadêmico atualmente em vigor, pensado em atuar em rede ou em articulação com outras universidades públicas brasileiras, implementando uma nova arquitetura curricular ${ }^{9}$. Para o então Reitor Naomar de Almeida Filho (2010), ${ }^{10}$ que liderou esse processo na UFBA, com isto, a graduação se renova, mas torna-se necessário recriar o modelo nacional de pós-graduação. Para ele, deve ser removido, antes de tudo, "o abismo entre graduação e pósgraduação, que trava a educação superior brasileira, herança do Parecer Sucupira de 1966 e da reforma universitária de 1968". Destaca a reestruturação curricular como uma mudança básica a ser realizada, ao explicar que:

Em todos os níveis, componentes curriculares serão organizados não por titulação, mas por nível de profundidade. Flexíveis, estarão abertos a qualquer aluno, de graduação ou de pós, que demonstre estar habilitado a cursá-los (ALMEIDA FILHO, 2010).

Ainda que partindo de premissas bem distintas, os argumentos dos autores, acima citados, apontam, pelo menos em parte, para a ultrapassagem de problemas identificados através da fala de nossos entrevistados.

As dificuldades de integração - ou articulação - entre a graduação e a pós-graduação no caso do ICI-UFBA estão presentes no discurso de praticamente todos os entrevistados, que lembram a ruptura existente

\footnotetext{
9 Dentro do Programa de Apoio a Expansão e Reestruturação das Universidades Federais (REUNI), outras instituições seguem essa tendência: UFSC, UFRN, UFCG, UFJF, etc.

${ }_{10}$ O professor Naomar de Almeida Filho foi reitor da UFBA nos dois últimos reitorados (2003-2006) e (20072010).
} 
entre uma graduação em Biblioteconomia ou Arquivologia e uma pósgraduação em Ciência da Informação. Dentre as sugestões apresentadas para a ultrapassagem do que eles veem como uma espécie de "fosso", citam a necessidade de maior articulação entre os currículos desses dois níveis de ensino; o recurso à possibilidade (real, no caso da UFBA), de graduandos cursarem, como alunos especiais, disciplinas da pósgraduação; maior interlocução entre os colegiados de graduação e pós; maior circulação de informações sobre as atividades da pós; e compartilhamento de espaços e equipamentos pelos dois níveis de formação ${ }^{11}$. O fortalecimento da interlocução entre a ANCIB e a ABECIN é visto como uma possibilidade de definição de políticas de áreas que contemplem a necessidade de articulação entre esses dois níveis de formação.

Com relação à questão da adequação do perfil do docente pósgraduado às necessidades da graduação, constatamos também que não existe unanimidade entre os respondentes; porém, ainda que com diferenças de visão - às vezes maiores, às vezes menores - o processo de qualificação docente, através da realização de mestrado e doutorado, é visto como algo que incide (ou pode incidir) muito positivamente sobre a graduação. Sobre essa questão, Varela, Castro e Guimarães (2008), na pesquisa que realizaram sobre a atuação profissional e a contribuição para o campo científico da área, dos egressos da pós-graduação do ICI/UFBA, que defenderam suas dissertações entre o período 1998 e 2006, constataram "que os graduados em biblioteconomia foram os que mais fortaleceram a área, com a publicação de artigos e participação em eventos", embora no momento em que foi realizada a pesquisa, essa participação ainda tenha sido considerada "pouco consistente para dar visibilidade à CI" (VARELA, CASTRO, GUIMARÃES, 2008, p. 85).

Possíveis "descompassos" existentes entre áreas - aquela em que o professor se gradua, aquela em que realiza sua pós-graduação e aquelas em que ele deve atuar como docente de graduação e de pós-graduação, neste caso, muitas vezes por imposições do planejamento acadêmico estão naturalmente na origem das reticências demonstradas por alguns. A existência de eventuais necessidades de "ajustamentos", não deve, entretanto, obscurecer as reais possibilidades de uma prática interdisciplinar que se abre com a diversidade de formações dos docentes envolvidos com ambos os níveis de formação e o que isto pode significar em termos de enriquecimento para a área.

De maneira geral, a pesquisa afigura-se, na fala dos respondentes, como um elemento central nesta articulação entre graduação e pósgraduação, ainda que se possa perceber diferentes avaliações de como eles veem como isso se dá na prática. Foram vários os que destacaram experiências bem sucedidas vivenciadas por eles em grupos de pesquisa que congregam estudantes de graduação e de pós-graduação, que se reúnem, constantemente, participam de um processo de troca de

\footnotetext{
${ }^{11}$ Cabe destacar que as questões de infraestrutura estão sendo enfrentadas e que está em condição avançada a construção de uma nova sede para o ICI.
} 
informações e provocam discussões, que acabam ecoando nas respectivas salas de aula.

Claro que se percebe, também, os limites dessa articulação, mesmo quando um grupo de pesquisa congrega estudantes de ambos os níveis, já que não necessariamente eles estão envolvidos nos mesmos projetos. Essa situação acaba até mesmo sendo relativamente comum, na medida em que os estudantes de pós estão envolvidos em projetos individuais (suas dissertações e teses) - ainda que, forçosamente, inseridos nos campos temáticos configurados pelo próprio grupo de pesquisa. Neste caso, torna-se fundamental estimular discussões coletivas internas ao grupo e que sejam capazes de gerar diálogo e interação entre os participantes dele. A possibilidade recente de se vincular bolsistas PIBIC a doutorandos, que atuariam como "tutores" daqueles é, com certeza, outro caminho que se abre, agora, para a ampliação dessa articulação.

Aumentar a oferta de bolsas de IC e democratizar o acesso a elas permitindo, por exemplo, que jovens docentes pesquisadores possam concorrer com sucesso na distribuição das bolsas - seriam, também, medidas que em muito contribuiriam para o sucesso da articulação entre graduação, pós-graduação e pesquisa.

Cabe aqui destacar, uma louvável iniciativa desenvolvida recentemente com o empenho da coordenação do PPGCI e da representação estudantil junto a essa coordenação: a realização, em junho de 2010, do I Seminário de Pesquisa do PPGCI/UFBA: integração graduação e pós-graduação (EDUFBA, 2010), seguido de sua segunda edição, em julho de 2011. Ambas as edições mantiveram uma participação expressiva de professores e alunos de ambos os níveis de ensino, incluindo aqueles alunos que não tinham qualquer tipo de bolsa e que se inseriam nos projetos, enquanto voluntários. Este momento ímpar de troca acadêmica entre a graduação e a pós-graduação sinaliza um esforço de articulação através da pesquisa, que deverá ter continuidade e que poderá propiciar bons resultados a curto e a médio prazos. Com essa perspectiva, uma terceira edição deste evento já está sendo pensada para o mês de julho de 2012.

Ainda que os pontos acima elencados tenham sido suscitados pelo estudo de caso em uma instituição específica, acreditamos que eles possam contribuir, também, para a reflexão sobre práticas e políticas acadêmicas em outras instituições. Em outro patamar, espera-se que eles contribuam, também, para uma reflexão sobre a necessidade de políticas de área que caminhem no sentido da consolidação da Ciência da Informação no Brasil. Neste caso, não se pode deixar de enfrentar o problema da grande desigualdade na distribuição regional entre os programas de pós-graduação e pesquisa no país, visto o enorme potencial que eles têm para dinamizar e enriquecer a formação dos jovens estudantes de graduação.

\section{Referências}


ALMEIDA FILHO, N. de. Pós-Graduação nova no Brasil. Folha de São Paulo, p. 8, 12 de novembro de 2010.

AMARAL, S. A. do. Programas de Pós-Graduação em Ciência da Informação: algumas considerações. In: WORKSHOP EM CIÊNCIA DA INFORMAÇÃO: POLÍTICAS E ESTRATÉGIAS DE PESQUISA E ENSINO DE PÒS-GRADUAÇÃO. Anais... Niterói: UFF; ANCIB, 2004. p. 58-66.

ANDRADE, J. B. de. Editorial. Química Nova, São Paulo, v. 22, n. 2, p.163, mar./abr. 1999.

ARBOIT, A. E.; BUFREM, L. S.; KOBASHI, N. Y. A institucionalização da Ciência da Informação no Brasil sob a ótica da evolução quantitativa dos cursos de graduação na área. Informação \& Sociedade: Estudos, João Pessoa, v. 21, n. 1, p.145-158, jan./abr. 2011.

BRASIL. Coordenação de Aperfeiçoamento de Pessoal de Nível Superior (CAPES). Documento de Área 2007-2009: Ciências Sociais Aplicadas I (Comunicação, Ciência da Informação e Museologia). 2010. Disponível em: <http://www.Capes.gov.br/avaliacão/documento-de-área-/3270>. Acesso em: 20 jan. 2011.

CURY, C. R. J. Graduação/Pós-Graduação: a busca de uma relação virtuosa. Edu. Soc, Campinas, v. 25, n. 88, p. 777-793, out. 2004.

KOBASHI, N. Y. A articulação entre a Pós-Graduação e a Graduação em Ciência da Informação num quadro de pesquisa e ensino interdisciplinares. In: WORKSHOP EM CIÊNCIA DA INFORMAÇÃO: POLİTICAS E ESTRATÉGIAS DE PESQUISA E ENSINO DE PÓSGRADUAÇÃO. Anais... Niterói: UFF; ANCIB, 2004. p. 143-158.

KOBASHI, N. Y. Notas sobre o papel da pesquisa em cursos de graduação. Transinformação, Campinas, v. 14, n. 2, p. 153-158, jul./dez. 2002.

RODRIGUES, M. E. F. Possibilidades de articulação entre o ensino e a pesquisa: proposições da ABECIN. In: WORKSHOP EM CIÊNCIA DA INFORMAÇÃO: POLÍTICAS E ESTRATÉGIA DE PESQUISA E ENSINO DE PÓS-GRADUAÇÃO. Anais... Niterói: UFF; ANCIB, 2004. p. 159-173.

UNIVERSIDADE FEDERAL DA BAHIA. Instituto de Ciências da Informação. Programa de Pós-Graduação em Ciência da Informação. Seminário de Pesquisa do PPGCI/UFBA, 1: integrando graduação e pós-graduação. Anais... Salvador: EDUFBA, 2010. CD-Rom.

UNIVERSIDADE FEDERAL DA BAHIA. Instituto de Ciência da Informação. Programa de Pós-Graduação em Ciência da Informação. Seminário de Pesquisa do PPGCI/UFBA, 2: integrando graduação e pós-graduação. Anais... Salvador: EDUFBA, 2011. CD-Rom.

VARELA, A.; CASTRO, M. I.; GUIMARÃES, I. B. Ciência da Informação: atuação profissional e as contribuições para o desenvolvimento do campo científico por parte dos egressos do PPGCI (ICI/UFBA). Ciência da Informação, Brasília, v. 37, n. 3, p. 76-87, set./dez. 2008. 